\title{
Longitudinal Predictors of Helicopter Parenting in Emerging Adulthood
}

Laura M. Padilla-Walker

Brigham Young University, laura_walker@byu.edu

Larry J. Nelson

Ryan D. McLean

Follow this and additional works at: https://scholarsarchive.byu.edu/facpub

Part of the Social and Behavioral Sciences Commons

\section{Original Publication Citation}

Nelson, L. J., Padilla-Walker, L. M., *McLean, R. (2020, onlinefirst). Parent, child, and relationship predictors of helicopter parenting in the transition to adulthood. Emerging Adulthood.

\section{BYU ScholarsArchive Citation}

Padilla-Walker, Laura M.; Nelson, Larry J.; and McLean, Ryan D., "Longitudinal Predictors of Helicopter Parenting in Emerging Adulthood" (2020). Faculty Publications. 5500.

https://scholarsarchive.byu.edu/facpub/5500

This Peer-Reviewed Article is brought to you for free and open access by BYU ScholarsArchive. It has been accepted for inclusion in Faculty Publications by an authorized administrator of BYU ScholarsArchive. For more information, please contact ellen_amatangelo@byu.edu. 


\section{Longitudinal Predictors of Helicopter Parenting in Emerging Adulthood}

\author{
Larry J. Nelson' ${ }^{(D,}$ Laura M. Padilla-Walker', and Ryan D. McLean'
}

Emerging Adulthood

202I, Vol. 9(3) 240-25।

(C) 2020 Society for the

Study of Emerging Adulthood

and SAGE Publishing

Article reuse guidelines:

sagepub.com/journals-permissions DOI: $10.1177 / 2167696820931980$ journals.sagepub.com/home/eax

@SAGE

\begin{abstract}
The purpose of this exploratory longitudinal study was to examine stability and change of helicopter parenting throughout the first few years of emerging adulthood and to examine child and parent-child relational factors that might predict helicopter parenting. Participants included 453 emerging adults from a northwestern city in the United States (5I\% female, 33\% single-parent families) who participated in a 10-year longitudinal study, with the current study examining ages 19-2I. Results revealed that (a) for both mothers and fathers, helicopter parenting decreased over time, (b) some child and relational factors predicted initial levels of helicopter parenting, but (c) the findings were somewhat different for mothers and fathers and for daughters and sons. The findings support the growing understanding that the links between helicopter parenting and child (mal)adjustment are nuanced and complex. Findings have implications for those who work with parents and young people in trying to promote flourishing during emerging adulthood.
\end{abstract}

\title{
Keywords
}

helicopter parenting, emerging adulthood, parenting, parent-child relationship

Researchers have attempted to better understand helicopter parenting in emerging adulthood. Helicopter parenting is when parents do for children what they should developmentally be able to do for themselves (Hunt, 2008; Padilla-Walker et al., 2019), such as settling disputes with employers or determining college majors or classes for emerging-adult children. Although news media often outline the negative outcomes associated with helicopter parenting, the empirical evidence provides more nuanced results (e.g., Kelly et al., 2017; Lindell et al., 2017; Nelson et al., 2015). However, when helicopter parenting is, or is perceived by emerging adults to be, implemented in a controlling way which undermines autonomy, results are more consistently associated with negative outcomes (e.g., Padilla-Walker \& Nelson, 2012). Most of the existing work, however, has employed crosssectional designs and is, therefore, limited in understanding the trajectory of helicopter parenting over time. Further, few studies have attempted to examine factors that may elicit helicopter parenting. Therefore, the 2-fold purpose of this exploratory examination was to examine (1) stability and change of helicopter parenting throughout the first few years of the transition to adulthood and (2) child and parent-child relational factors that predict helicopter parenting in emerging adulthood.

\section{Family Systems Theory and Family Life-Course Perspective}

Family Systems Theory suggests that the family provides an environment within which individual members are impacted by and impact each other as an interconnected set (or system) of relationships. Relatedly, a Family Life-Course Perspective suggests that the trajectories of family members are interdependent such that there is a consistent interplay between the individual development of, in this case, emerging-adult children and other family members (Aquilino, 2006; Elder, 1994). These theoretical lenses suggest that family relationships change over time as a function of the development of individuals in a family, and, simultaneously, life trajectories of family members are influenced by changes in family relationships over time.

The initial years of emerging adulthood present a time of rather dramatic and novel life transitions (i.e., change) such as young people leaving the family home and beginning college and/or work. Furthermore, emerging adulthood marks a period of change in the relationship between emerging adults and their parents, which, in turn, impacts the trajectory of emerging-adult children. In sum, these theoretical perspectives highlight the need to understand the bidirectional processes involved within family systems. Specifically, it is important to understand that just as children's developmental trajectories

\footnotetext{
'Brigham Young University, Provo, UT, USA

Corresponding Author:

Larry J. Nelson, PhD, Brigham Young University, Provo, UT 84602, USA.

Email: larry_nelson@byu.edu
} 
are influenced by their parents' behaviors (e.g., parenting styles and practices), parental behaviors are similarly influenced by aspects of their children (e.g., behaviors parents want to encourage or stop). Thus, to understand any process in a family (e.g., helicopter parenting), it is important to understand factors that may be related to, or even elicit, parental behaviors.

\section{Helicopter Parenting During Emerging Adulthood}

It is well established that when parents support their children's developing autonomy, better outcomes exist such as overall adjustment (Rodríguez et al., 2019), prosocial behavior (Gerardy et al., 2015), and emotional regulation (Brenning et al., 2017). Conversely, intrusive and controlling parenting tends to be associated with more negative adjustment throughout development (e.g., Nelson et al., 2011; Olsen et al., 2002; Pettit et al, 1996). There is reason to believe that oversolicitous and intrusive forms of parenting, such as helicoptering, tends to be particularly problematic in emerging adulthood as it is a time during which young people both desire and are working toward greater self-reliance (e.g., Arnett, 2004). Hence, a major role of parents during this time is to foster their emerging adults' individuation by granting more autonomy to them while still lending support (Aquilino, 1997, 2006). When parents begin to interfere with those strivings toward self-reliance by employing helicopter parenting, it should not be surprising that problems may emerge in areas such as academics (Luebbe et al., 2018; Padilla-Walker \& Nelson, 2012; Schiffrin \& Liss, 2017), peer relationships (van Ingen et al., 2015), risk behaviors (Nelson et al., 2015), and overall well-being (e.g., Bradley-Geist \& Olson-Buchanan, 2014; LeMoyne \& Buchanan, 2011; Segrin et al., 2012), especially for daughters (Kouros et al., 2017).

It should be noted, however, that recent work has identified various implementations of helicopter parenting (Luebbe et al., 2018; Padilla-Walker et al., 2019), with more controlling- and autonomy-limiting forms being associated with detrimental child outcomes, while types more indicative of warmth, involvement, or support could be positive (Fingerman \& Yahirun, 2016; Nelson et al., 2015), including higher closeness with parents (Kelly et al., 2017; Padilla-Walker et al., 2012) and lower tuition-related debt (Lowe et al., 2015). Positive and null findings are common among parent-reported helicopter parenting (Segrin et al., 2013), possibly because the parent does not view "helping" a child as potentially problematic (i.e., limiting of autonomy) or simply feels that the benefits of their involvement outweigh the consequences of the lack of autonomy. However, especially when considering the emerging adults' perspective, there is growing evidence that helicopter parenting is linked to indices of floundering in emerging adulthood, especially when it is combined with other forms of control (e.g., psychological control; Padilla-Walker et al., 2019) and/or is lacking in warmth (e.g., Nelson et al., 2015).

Despite numerous contributions, there are a number of limitations within the extant research examining helicopter parenting. Notably, most of the work examining helicopter parenting during emerging adulthood has been cross-sectional in nature which limits our understanding of helicopter parenting in a number of ways. First, we know very little about the stability and change of helicopter parenting throughout emerging adulthood. Second, cross-sectional designs preclude the ability to examine directionality in the relations between helicopter parenting and indices of adjustment/maladjustment. Specifically, most of the extant cross-sectional work has posited that helicopter parenting predicts the indices of maladjustment in young people. However, because family systems consist of individuals with interconnected lives, there may be characteristics of the individuals (i.e., children and parents) or in the system itself (e.g., home environment, aspects of the parent-child relationship) that elicit more controlling parenting, but we know very little about factors (child, parent, or systemic) that might predict the use or trajectories (stability and change) of helicopter parenting over time. To address these limitations, the purpose of this longitudinal study was to examine stability and change of helicopter parenting throughout the first few years of emerging adulthood and to examine child and parent-child relational factors that predict helicopter parenting in emerging adulthood.

\section{The Current Study}

The theoretical lenses of Family Systems Theory and Family Life-Course Perspective demonstrate that family relationships change over time as a function of the development of individuals in a family, and, simultaneously, life trajectories of family members are influenced by changes in family relationships over time. Emerging adulthood marks a significant period of transition, wherein parents and emerging adults must navigate the changing family roles, boundaries, and structures caused by emerging adults' need and desires for greater autonomy as they begin the process of becoming independent adults. This time of change in the family system might be met with changes in how parents choose to parent with some starting to grant more and more autonomy and others attempting to maintain control through parenting strategies such as helicopter parenting. Unfortunately, no study has longitudinally examined aspects of stability and change in helicopter parenting during emerging adulthood. Thus, the first purpose of the study was to longitudinally examine child-reported rates of helicopter parenting for both mothers and fathers from the ages of 19-21.

It was hypothesized that helicopter parenting would be higher early in emerging adulthood, but as emerging adults begin the process of transitioning into self-reliant, independent adults, it would be expected that the system would change accordingly and helicopter parenting would decrease for both mothers and fathers. This expectation was based on work examining autonomy granting across development. For example, work shows that parental attempts to limit their children's behavioral autonomy tend to decrease across development (Keijsers \& Poulin, 2013), while parental granting of autonomy tends to increase (Keijsers et al., 2016; see Soenens et al., 2019, 
for a review). Hence, this work would suggest that parents tend to decrease their efforts at limiting emerging adults' autonomy, and, thus, levels of helicopter parenting would be highest early in emerging adulthood but decline over time.

However, there is reason to expect some differences in the trajectories of helicopter parenting based on the gender of the child and the gender of the parent. Evidence shows that mothers tend to overparent more than fathers in emerging adulthood (Rousseau \& Scharf, 2015) and that parents tend to be more involved, generally, with their daughters than their sons during emerging adulthood (e.g., Bradley-Geist \& Olson-Buchanan, 2014). This work led us to hypothesize that mothers would engage in higher levels of helicopter parenting than fathers, and parents of daughters would engage in more helicopter parenting than parents of sons.

The second purpose of the study was to examine child and parent-child relational factors that predict the trajectories (use, stability, and change) of helicopter parenting in emerging adulthood. As noted, the cross-sectional designs employed in most of the extant research have found associations between helicopter parenting and various indices of maladjustment. Most often, the conceptual framework is that helicopter parenting is the causal mechanism in those associations. As noted, though, Family Systems Theory and Life-Course Perspective suggest that family processes such as parenting are not unidirectional in nature but instead are influenced by children and the nature of the parent-child relationship. Hence, we hypothesized that there would be factors that may be related to, or even elicit, helicopter parenting.

In the case of child factors, parental use of helicopter parenting may be affected by the extent to which parents believe the emerging-adult children are doing well versus poorly in the process of transitioning to adulthood. For example, if parents perceive that their children are wiling away their time (e.g., video games), or struggling emotionally (e.g., depression), or not engaged in productive endeavors (e.g., school, work), then they may feel the need to become more actively involved, believing that their assistance will yield some sort of favorable turning point for their children (Fingerman et al., 2012). Again, it is important to note that whether or not a behavior is actually a risk factor for floundering may matter less than whether parents perceive some aspect of their child's life to be counterproductive (e.g., Mahbod \& Fouladchang, 2018) to making progress toward adulthood. For example, there is debate as to the extent that video game use is problematic (see Aarseth et al., 2017) but our own work, emerging from our various projects and data sets, has repeatedly found video game use (especially violent video game use) to be linked with indices of maladjustment (e.g., greater drug and alcohol use; Padilla-Walker et al., 2010), and negatively related to indices of adjustment (e.g., empathic concern, prosocial behavior; Padilla-Walker et al., 2012) in emerging adulthood. More important than actual findings regarding video game use though is how parents might see their children's behavior. Work by Russell and Johnson (2017) found that parents felt their sons who spent a lot of time playing video games were missing out on aspects of their life due to their gaming and were not meeting their full potential. It is this perception that video games use (and other behaviors like it) may be interfering with their children's development that may elicit more hovering behaviors. Taken together, if parents see a behavior as generally harmful (e.g., driving while drunk), or simply counterproductive to doing well in other areas of their life (e.g., academic performance), mothers and fathers may proactively respond with more control in an effort to bring about perceived favorable outcomes (Fingerman et al., 2012)

In sum, it was hypothesized that child factors that pose challenges (real or perceived by parents) to flourishing would elicit more parental overinvolvement whereas child factors indicating well-being would not. To test this hypothesis, a variety of variables were selected to capture the type of child factors that parents might respond to out of concern for their child's wellbeing. Specifically, based on our own work and that of others, we selected variables that may be perceived as counterproductive or have been found to represent indices of floundering. For example, our own research shows that those who are floundering in emerging adulthood experience higher levels of depressive symptoms, play more video games, and have more externalizing problems (e.g., engage in more risky behaviors) while those who are flourishing experience more selfregulation (Nelson \& Padilla-Walker, 2013). Hence, it was expected that depressive symptoms, externalizing problems, and symptoms of video game addiction would predict use of helicopter parenting while self-regulation and school engagement would not.

In regard to aspects of the parent-child relationship that might elicit helicopter parenting, there is evidence that parental warmth and/or psychological control are important to examine when considering helicopter parenting. First, it should be noted that helicopter parenting, psychological control, and parental warmth are distinct aspects of parenting but related in important ways. For example, Padilla-Walker and Nelson (2012) found that helicopter parenting loaded on a separate factor from both behavioral and psychological control and that helicopter parenting was not associated with warmth but positively associated with psychological control but not at levels suggesting complete overlap. In another study examining warmth as a moderator, it was found that parenting was associated with lower levels of self-worth and higher levels of risk behaviors for those emerging adults who reported low levels of maternal warmth, but not for those reporting high levels of warmth (Nelson et al., 2015). In other words, they found that helicopter parenting characterized by warmth did not help their emergingadult children, but it seemed to protect against some of the negative effects of intruding upon young people's autonomy. Another study examining profiles of helicopter parenting found emerging adults whose mothers were average on helicopter parenting but high on warmth were doing better (e.g., higher school engagement, less depression) than a group whose mothers were average in helicopter parenting and high in psychological control (Padilla-Walker et al., 2019). 
Taken together, existing work suggests that there may be some parent-child relationships characterized by parental psychological control in which the intent of helicopter parenting is to limit autonomy but in other relationships that are characterized by parental warmth the intent of helicopter parenting may be to show support (Burke et al., 2018; Fingerman \& Yahirun, 2016). Thus, it was hypothesized that both parental warmth and parental psychological control, respectively, as well as relationship quality, would predict initial use of helicopter parenting, but that parental warmth and relationship quality would predict declines in the use of helicopter parenting over time (as young people "settle into" emerging adulthood) whereas parental psychological control would not (as these parents may simply want to maintain control).

\section{Method}

\section{Participants and Procedure}

Participants included 453 emerging adults from a northwestern city in the United States who participated in a 10-year longitudinal study starting at age 11.5 at Wave 1 (51\% female, $33 \%$ from single-parent families). Over $90 \%$ of those who participated at Wave 1 also participated at Wave 10. Because helicopter parenting was not measured until Wave 8, which signified the transition to adulthood for most in the study, in the current study, we only used data from when children were in ages 19, 20, and 21. All emerging adults reported on their mother figure and the majority also reported on their father figure $(n=401)$. In terms of ethnicity, $67 \%$ of participants were European American, $11 \%$ were African American, and $22 \%$ were multiethnic or other ethnicities. At age 19 , the majority of young people $(74 \%)$ reported attending college or technical school, $16 \%$ indicated not attending college, and $6 \%$ reported being in high school or having just graduated from high school. In regard to living situation, $57 \%$ of participants indicated living with parents and 35\% reported either living on campus or in an apartment/house with roommates. Regarding family income, $18 \%$ of parents reported a family income less than US $\$ 40,000$ per year, $48 \%$ made between US $\$ 40,000$ and $\$$ US 100,000 a year, and $34 \%$ made more than US\$100,000 per year.

Upon approval of our institutional review board (Brigham Young University, study approval number: F18321, study name: Flourishing Families), data were collected each year during the summer. For the first five waves of the study, questionnaires were administered in the family home, but Waves 610 were collected using an online survey platform (Qualtrics) to accommodate children moving out of the home. As each wave of data included an age range of 4 years, the data for this study were restructured by age to examine helicopter parenting profiles when emerging adult children were 19, 20, and 21 years old so that they would have transitioned out of high school into college or work. Questions about helicopter parenting were not included in the data set until Wave 8 and were only given to participants if the child had already graduated from high school. This resulted in 355 participants at Wave 8, 423 at Wave 9, and 424 at Wave 10 who were given the measure. Data restructuring resulted in a larger proportion of missing data at ages 18 and 21 because not all participants were 18 when they graduated high school and not all participants reached age 21 before Wave 10 . There were not sufficient data at age 18 on helicopter parenting, so we examined change from ages 19 to 21 .

\section{Measures}

Helicopter parenting. Emerging adults reported on mother and father helicopter parenting at ages 19,20 , and 21 using a 5item helicopter parenting scale asking about the degree to which their parents made important decisions for them (Padilla-Walker \& Nelson, 2012). Participants answered questions on a 5-point scale ranging from 1 (not at all like her) to 5 (a lot like her). Sample questions consisted of "my parent intervenes in settling disputes with my roommates or friends" and "my parent solves any crisis or problem I might have" $(\alpha=$ .81 to .83$)$.

Self-regulation. The ability to regulate negative emotions and disruptive behavior and to set and attain goals was assessed at age 19 using a modified 13 -item measure (Novak \& Clayton, 2001). Responses ranged from 1 (never true) to 4 (always true). Sample items included: "I have a hard time controlling my temper" and "I get distracted by little things." Higher scores represent greater ability to regulate negative emotion/behavior and to reach goals $(\alpha=.83)$.

School engagement. At age 19, emerging adults who were attending school reported on their own levels of functioning at school based on a 10-item modified version of a School Engagement Scale (Fredricks et al., 2004). Sample items included, "I pay attention in class" and "I am interested in the work at school" $(\alpha=.83)$. Responses ranged from 1 (strongly disagree) to 5 (strongly agree), with higher scores indicating greater school engagement.

Depression. Child's depression was assessed at age 19 using the 20-item self-report Center for Epidemiologial Studies - Depression inventory (CES-D) (Weissman et al., 1980). Participants responded by rating the degree to which they have experienced each item in the past week, with a Likert-type scale ranging from 1 (not at all) to 4 (a lot). Sample items included, "I was bothered by things that usually don't bother me," with higher scores indicate greater depressive symptoms $(\alpha=.92)$.

Externalizing behavior. Participants reported on their own externalizing behavior at age 19 using 9 items (Barber et al., 2005) including "I lie or cheat" and "I use alcohol or drugs." Participants rated how true each statement was about them, with responses ranging from 0 (not true) to 2 (often true). Higher scores represented higher levels of delinquent behavior $(\alpha=.72)$. 
Symptoms of video game addiction. Symptoms of video game addiction were assessed at age 19 using 11 items (e.g., "Do you need to spend more and more time and/or money on video games in order to feel the same amount of excitement?" and "Over time, have you been spending much more time thinking about playing video games, learning about video game playing, or planning the next opportunity to play?"; Gentile, 2009). Participants responded 0 (no), 1 (sometimes), 2 (yes) with "yes" or "sometimes" considered a symptom of pathological gaming. Items were summed with higher scores suggesting greater pathological symptoms. As a frame of reference for interpreting means, the literature generally considers pathological gaming to be present if teens score positive on 6 of the 11 symptoms on the scale (Gentile, 2009).

Parental warmth. Participants reported on mother and father warmth at age 19 using the 5-item warmth/support subscale of the Parenting Styles and Dimensions Questionnaire-Short Version (Robinson et al., 2001). Questions included behaviors indicative of warmth such as, "My mother is responsive to my feelings and needs" $(\alpha=.89, .91)$. Responses ranged from 1 (never) to 5 (always), with higher scores representing greater maternal and paternal warmth.

Parental psychological control. Emerging adult children reported on mother and father psychological control at age 19 using the 8-item Psychological Control Scale (Barber, 1996). Sample items included, "My parent interrupts me" and "My parent will avoid looking at me when I have disappointed her/him." Responses ranged from 1 (never) to 5 (very often) with higher scores indicating a greater degree of maternal and paternal psychological control $(\alpha=.90, .91)$.

Parent-child relationship quality. Parent-child relationship quality was assessed at age 19 using 6 items $(\alpha=.92)$ from the Social Provisions Questionnaire (Carbery \& Buhrmester, 1998). Emerging adults answered questions on a 5-point scale ranging from 1 (little or none) to 5 (the most) about their relationship with their mother and father. Sample questions included, "How often do you turn to this person for support with personal problems?" and "How happy are you with the way things are between you and this person?"

\section{Results}

\section{Descriptive and Missing Data Analyses}

Data were examined for univariate and multivariate outliers, and none were identified. Descriptive statistics and correlations for all continuous variables are shown in Table 1. Of note, patterns of correlations were somewhat different for the child's perception of mother and father helicoptering. To assess the patterns of missing data, we conducted $t$ tests to determine whether there were differences on study variables as a function of whether or not data were missing to some degree or fully complete. A dichotomous variable was created indicating

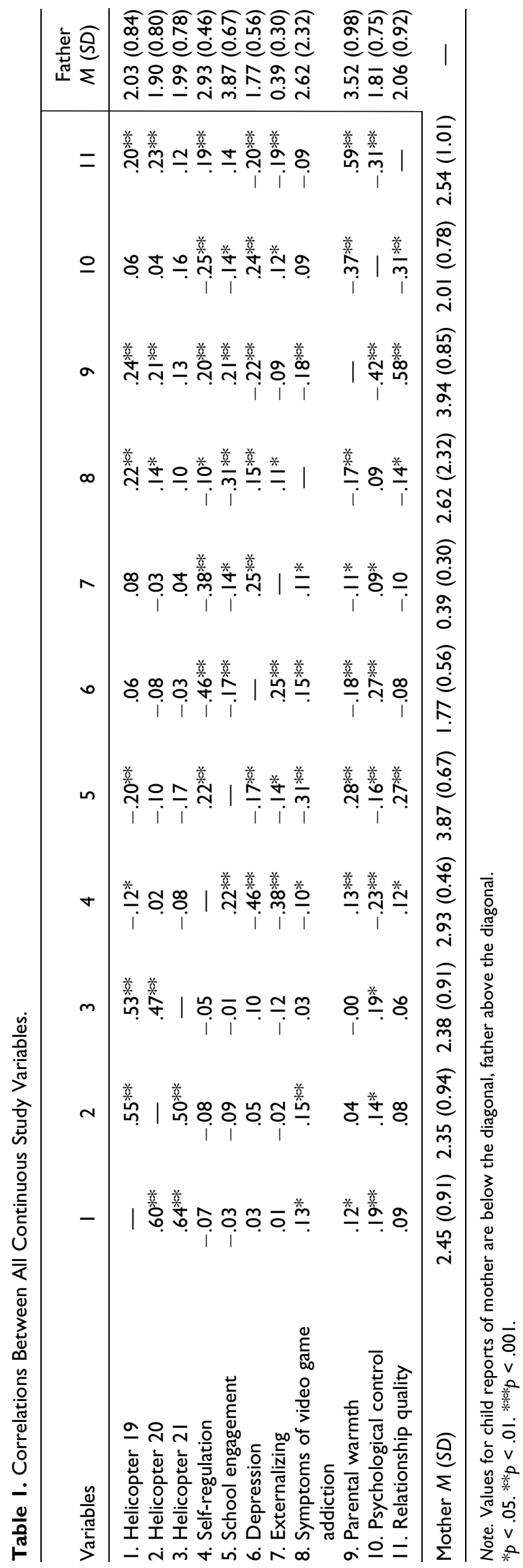




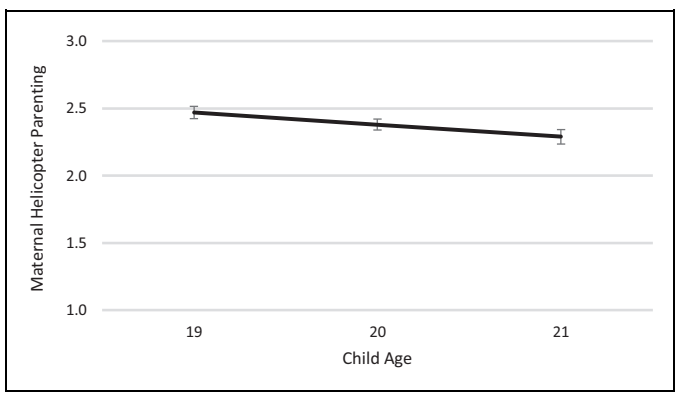

Figure I. Growth curve of maternal helicopter parenting.

missingness with $0=$ no missing data and $1=$ at least one missing data point. We then conducted $t$ tests to determine whether any study variables differed as a function of missingness. This included $17 t$ tests in all, none of which were statistically significant, suggesting that data were missing at random. Missing data were dealt with using Full Information Maximum Likelihood (FIML) in Mplus, which is recommended for data that are missing at random or completely at random (Enders \& Bandalos, 2001). Thus, the full sample of 453 adolescents (401 for father-reported data) was used in analyses.

\section{Changes in Helicopter Parenting Over Time}

To address the first research question, growth curve analyses at ages 19, 20, and 21 were conducted using Mplus software, separately for child report of maternal and paternal helicopter parenting. Intercepts and slopes were explored using the MODEL TEST command to determine whether they differed as a function of the child's biological sex. The mother model, $\chi^{2}(1)=0.58, p$ $=.45$, comparative fit index $(\mathrm{CFI})=1.00$, root mean square error of approximation (RMSEA) $=0$, had both a significant intercept $(I=2.47, S E=.05, p<.001)$ and a significant negative slope $(S=-.09, S E=.03, p<.01)$. Exploration as a function of child sex did not reveal a decrease in model fit when intercept and slope were constrained to be equal for young men and young women, so we maintained the single growth curve for the mother model (see Figure 1). The father model, $\chi^{2}(1)=2.65, p=.10$, $\mathrm{CFI}=0.99, \mathrm{RMSEA}=.06$, had both a significant intercept $(I=$ 2.01, $S E=.04, p<.001)$ and a significant negative slope $(S=$ $-.07, \mathrm{SE}=.03, p<.05)$. Exploration as a function of child sex revealed a decrease in model fit when the intercept of paternal helicoptering was constrained to be equal across young men and young women (Wald $=12.81, p<.001$ ), but there was no difference when constraining the slope. Analyses revealed higher initial levels of paternal helicopter parenting for young men $(I=$ $2.16, S E=.06, p<.001)$ compared to young women $(I=$ $1.90, S E=.05, p<.001$; see Figure 2).

Using the MODEL TEST command, we also compared the single maternal and paternal growth curve to see whether the intercept or slope differed from one another. Model fit decreased significantly when the intercept was constrained to be equal across mothers and fathers (Wald $=101.43, p<$ $.001)$. Model fit did not decrease when the slope was constrained to be equal across mothers and fathers. Taken together,

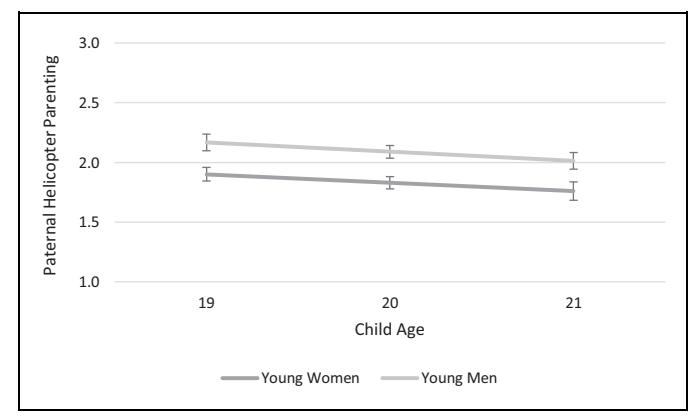

Figure 2. Growth curves of paternal helicopter parenting by child sex.

this suggests that mothers had higher levels of helicopter parenting when their children were at age 19 than did fathers, but that rates of helicopter parenting decreased similarly over time for both mothers and fathers.

\section{Predictors of Initial Levels and Change in Helicopter Parenting}

Next we explored variables at age 19 that might be associated with initial levels and change in helicopter parenting over time. When exploring multiple group analysis as a function of child gender, we used the criterion that a drop in CFI > .01 represented significant change as a function of constraints (Little, 2013). We also used the MODEL TEST command to explore each constraint if the initial comparison suggested a decrease in model fit when comparing a fully constrained to a fully unconstrained model. Given the number of tests conducted, we utilized BenjaminiHochberg adjusted $p$ values (Benjamini \& Hochberg, 1995).

For the mother model, there was no significant decrease in model fit when comparing a fully unconstrained model to a fully constrained model, so we considered child sex only as a predictor and not a moderator, $\chi^{2}(12)=5.73, p=.46$, CFI $=1.00$, RMSEA $=.01$. Findings revealed that maternal warmth and maternal psychological control were associated with higher initial levels of helicopter parenting (see Table 2). It is of note that this represents only 2 significant covariates of the 12 considered, and none of the covariates significantly predicted change in helicopter parenting.

For the father model, there was a significant decrease in model fit when comparing a fully unconstrained model to a fully constrained model (CFI change from .93 to .85 ). Thus, after constraining one path at a time, the best fitting model was a multiple group model with 5 of the 22 paths left free to vary as a function of child sex, $\chi^{2}(39)=39.28, p=.46, \mathrm{CFI}=.99$, RMSEA $=.01$. Those paths included externalizing behavior and symptoms of video game addiction on the intercept, and externalizing behavior, warmth, and psychological control on the slope. Findings suggested that for young women, paternal warmth was associated with higher initial levels of paternal helicopter parenting but a steeper decrease over time (see Table 2). For young men only, symptoms of video game addiction and paternal warmth were associated with higher initial levels of paternal helicopter parenting. It is of note that this 
Table 2. Child, Parent, and Relational Predictors of Helicopter Parenting.

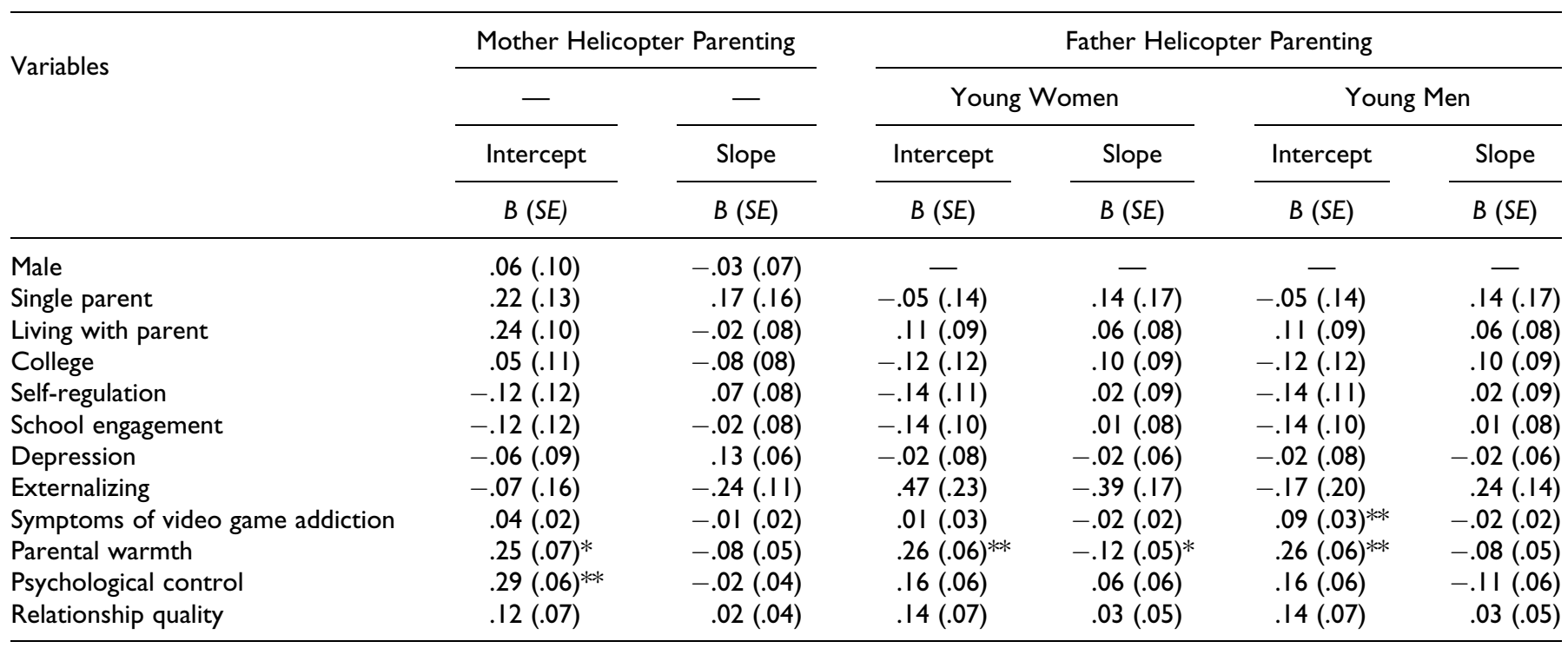

Note. Benjamini-Hochberg adjusted $p$ values.

$*_{p}<.01 . *_{p}<.001$.

represents only 2 significant covariates of the 12 considered, and only one of the covariates significantly predicted change in helicopter parenting, for young women only.

\section{Discussion}

Emerging adulthood is a time during which young people both desire and are working toward greater self-reliance (e.g., Arnett, 2004). Hence, a major role of parents during this time is to foster their emerging adults' attempts to develop the attributes of adulthood by granting more autonomy to them while still lending support. Therefore, parenting that limits child autonomy may pose problems for healthy adjustment. Unfortunately, due to the cross-sectional nature of most of the existing work, we know little about trajectories of helicopter parenting or about factors that may lead some parents to engage in helicoptering parenting. Therefore, results of the current exploratory, longitudinal study make several important contributions to our understanding of helicopter parenting in emerging adulthood. Specifically, despite the fact that the majority of child and family factors examined were not related to helicopter parenting, results did provide (a) information regarding the trajectories of helicopter parenting in early emerging adulthood, (b) tentative evidence that both child and parent-child relational factors predict helicopter parenting, and (c) indication that the gender of both parents and emerging adults matter when examining trajectories and predictors of helicopter parenting in emerging adulthood.

\section{Change in Helicopter Parenting Over Time}

First, it is interesting to note that children's perceptions of helicopter parenting were highest at age 19 but then declined significantly but only slightly over the next few years. Seeing rates of helicopter parenting that are highest (although not necessarily "high") early in emerging adulthood may, from a systems perspective, reflect a system that is trying to regain a state of equilibrium in the face of transition. In this reorganization of the family system, a small number of parents (at least according to their children) may parent their emerging adults with a level of control that is inappropriate for their ages but then, in adjusting to the demands of the time period (i.e., children's desires for autonomy, etc.), levels of helicopter parenting diminish over time.

That being said, overall levels of helicopter parenting were quite low, with the average somewhere between "not like my parent" and "somewhat like my parent" for mothers and even lower for fathers. These levels add to research suggesting that helicopter parenting generally does not occur at high levels (despite media attention to the contrary). Indeed, it appears that most parents recognize it as a time to allow their children to begin to make more decisions on their own. Also, the initial low levels of helicopter parenting were then followed by perceived declines of helicoptering over time. These declines were likewise small in magnitude (e.g., mean levels of maternal helicopter parenting dropped from 2.45 at age 19 to 2.38 at age 21 , which is a drop of only 0.07 on a $1-5$ scale, or about $1.8 \%$ of the distance between the scale's maximum and minimum scores) but nevertheless reflect a developmentally appropriate approach to granting young people more autonomy as they progress through the third decade of life.

It should be noted that although both mothers and fathers declined in their use of helicopter parenting over the years, mothers engaged in $9 \%$ more helicopter parenting to begin with than fathers and fathers' initial levels were $5.3 \%$ higher for sons than daughters. Prior cross-sectional research employing parent ratings to investigate this trend have found similar results 
(Rousseau \& Scharf, 2015), so our findings support the notion that mothers and fathers differ in their use of control. However, because the current study employed child reports of parenting behavior, it is also possible that children simply perceive their parents' helicoptering somewhat differently depending on whether it comes from mothers versus fathers (Schiffrin et al., 2019). Regardless, the findings point to the need to consider the gender of the parent when considering the stability and change of helicopter parenting during the transition to adulthood.

Finally, it is important to note that a discussion of the low levels of helicopter parenting is not intended to diminish the fact that some parents may still go too far with their control by doing for their children what they developmentally should be doing for themselves. A discussion that focuses on low levels of helicopter parenting and its stability and change based on the gender of parents and children is simply meant to underscore that the associations between helicopter parenting and child (mal)adjustment are nuanced and complex. In other words, we are starting to see a picture that suggests that helicopter parenting does not occur that often and the extent to which (if at all) it is related to outcomes may depend upon numerous factors including the gender of the parent, gender of the child, the presence of parental warmth or other forms of parental control (e.g., Nelson et al., 2015; Padilla-Walker et al., 2019), and how it is perceived by emerging-adult children (Schiffrin et al., 2015; Van Ingen et al., 2015).

\section{Child Predictors of Helicopter Parenting}

It was hypothesized that child factors would predict the use of helicopter parenting across the early years of emerging adulthood. Overall, surprisingly few child factors significantly predicted the use of helicopter parenting, but they nonetheless make several important contributions. First, it appears that child gender plays an important role. As noted, it was found that fathers' initial levels of helicopter parenting were higher for sons than daughters. Thus, in addition to the necessity to consider the gender of the parent when examining helicopter parenting, the findings point to the need to consider the gender of the child when examining the use of and change in helicopter parenting.

In order to better understand why fathers appear to hover over their sons more than their daughters, it may be important to understand another child factor that significantly predicted initial levels of helicopter parenting. Specifically, for fathers of sons, symptoms of video game addiction were linked to higher initial levels of helicopter parenting. This may be a response to something that fathers see as counterproductive to making strides toward adulthood. For example, if parents perceive that their sons are wiling away their time (e.g., video game use), then they may feel the need to become more actively involved. It is important to note that this association between symptoms of video game addiction and helicoptering parenting for fathers of sons was the only significant association for video game use and the effect size was small. Indeed, with a mean of 2.62 on a scale on which concern over pathological gaming does not exist until a person responds positively on 6 of the 11 symptoms (Gentile, 2009), there is little to suggest that gaming was a significant problem for the majority of the sample (although the fact that this variable was selfreported by emerging adults leaves the possibility of underreporting one's use of video games). Taken together, caution should be made so as to not overstate one small finding related to video games. However, we should likewise be careful not to entirely dismiss it, as evidence shows that parents of emergingadult sons do worry that spending a lot of time playing video games can interfere with their sons reaching their potential (Russell \& Johnson, 2017), and, thus, video game use may in fact be a factor (albeit small) to which parents are responding. More importantly, though, video game use is just one behavior that might elicit parental concern, so although a singular and small finding, it may nevertheless point to the need to examine other possible child behaviors to which parents may respond out of concern.

With this in mind, it is interesting to note that at the bivariate level, for fathers, there was a negative correlation between school engagement and self-regulation and helicopter parenting at Time 1 . Whereas perceived negative behaviors may elicit more parental involvement, these results may provide evidence that if children are doing well (e.g., self-regulated, engaged in school), then most parents do not see the need to step in and do things for their emerging adults.

Taken together, it is possible that some children's characteristics may influence what parenting strategies parents employ (e.g., helicopter parenting) and how long they employ them. Future work is needed to determine whether the choice of how to respond (e.g., helicopter parenting) is the appropriate response for the situation (e.g., symptoms of video game addiction), but these findings make important, albeit tentative, contributions by suggesting that parental behavior in emerging adulthood might be a response to aspects of their children's lives.

\section{Parent-Child Relationship Predictors of Helicopter Parenting}

Finally, it is important to note the findings related to parentchild relationship factors that might predict helicopter parenting. Although the overall quality of the parent-child relationship was not associated with helicopter parenting at any time point, results found that specific aspects of parenting were related to helicoptering. Specifically, for mothers, initial levels of maternal helicopter parenting were positively linked with maternal warmth and psychological control. For fathers of young women, warmth was associated with higher initial levels of helicopter parenting but also greater decreases over time, whereas for fathers of young men, warmth was associated only with higher initial levels of helicoptering. These findings (although small in number and effect size, in that a one-unit increase in parental warmth or control was associated with a roughly 0.25 increase in helicopter parenting, which is 
approximately a $5 \%$ increase on the $1-5$ scale) add to the growing body of research showing that aspects of warmth and psychological control are important to consider in relation to helicopter parenting. Specifically, the extant work shows that while helicoptering is a distinct form of parenting in emerging adulthood (Padilla-Walker \& Nelson, 2012), it is related to psychological control and warmth in important ways. For example, evidence shows that when helicopter parenting is combined with warmth it is associated with fewer maladaptive outcomes than when it is combined with psychological control (e.g., Nelson et al., 2015; Padilla-Walker et al., 2019).

The results support the growing notion that helicopter parenting should not be examined in solitude but rather in the context of other relationship factors. However, much of the existing work has examined the interaction of helicopter parenting and warmth and psychological control, respectively, while the present findings suggest that warmth might predict the use of helicopter parenting over time. Specifically, the findings add to the evidence showing that parental warmth and psychological control are related in complex ways to helicopter parenting by revealing that they are related to both its initial use in emerging adulthood and to its decline over time. For example, it may be that these findings reflect warm parents who employ helicopter parenting as an attempt to be supportive in the initial stages of their child's transition to adulthood but are then very responsive to their child's need for autonomy and begin to helicopter less and less. This explanation of the findings is purely speculative but points to the need for more work that examines how and when warmth might predict the use of helicopter parenting versus when it might mediate or moderate the links between helicopter parenting and indices of adjustment and maladjustment in emerging adulthood.

\section{Limitations, Future Directions, and Conclusion}

Although this study contributes meaningfully to our understanding of helicopter parenting in emerging adulthood, it is not without limitations. First, participants were relatively homogeneous in terms of ethnicity and socioeconomic status. Parents who are struggling financially, or who possess certain expectations for child behavior based on cultural values governing what should occur in the transition to adulthood, may approach parenting differently than what was captured in this study. Future research should continue to explore these questions with more diverse samples. Second, all of the variables in the study were child-reported which means findings may have been influenced by both shared method and shared reporter variance. Future studies should consider both parent and child perceptions of helicopter parenting and its correlates. It may also be important for researchers to determine whether helicopter parenting is motivated by the child's request for more parental support or by the parent's desire for control. Both alternatives are plausible and research has not yet made this distinction.

Next, despite the longitudinal nature of the study, questions remain regarding causality. Specifically, it is not known whether symptoms of video game addiction or helicopter parenting came first at age 19. It is possible that sons could have retreated into playing video games because their fathers were so controlling prior to age 18 . Hence, the study provides insight into the stability and change of helicopter parenting across the early years of emerging adulthood, but work is needed to understand how child and parenting factors in adolescence might be related to trajectories of parenting in emerging adulthood. Finally, the study employed only a limited number of variables to test the theoretical notion that multiple aspects of the family system influence the use of helicopter parenting. There are a number of other child (e.g., shyness, assertiveness, external versus internal motivations) and relational (e.g., communication patterns) factors that need to be examined as well as parent factors (e.g., personality characteristics, expectations for children) and other aspects of the familial system (e.g., siblings) that might be playing a role. Nevertheless, the findings suggest that additional work investigating individual differences is warranted to help us fully understand why this infrequently employed but potentially problematic form of parenting may be used in emerging adulthood.

Indeed, despite these limitations, this study makes numerous contributions to our understanding of helicopter parenting in emerging adulthood. Namely, this is the first study to consider helicopter parenting over time and illustrates the stability and change of helicopter parenting throughout the transition to adulthood. Additionally, this study identifies important child and relational predictors of helicopter parenting while also highlighting important null findings. Findings from the study may be used by educators and clinicians to help families understand individual child and relationship factors which, when understood, can help parent-child dyads find a balance between control and support which will strengthen parentchild relationships and facilitate healthy development of emerging adults. Specifically, those who work with young people may be able to help emerging adults see that their own choices and behaviors might be a stimulus for what their parents may do. This may help them understand that if they want to see a change in the relationship with their parents that they will need to be part of that change. Likewise, in working with parents, educators and clinicians can help parents see that they may be reacting to their children's behaviors in ways that make the situation worse. Helping both young people and parents see the reciprocal nature of their relationship can help them be more intentional in what they each, respectively, contribute to the family system.

\section{Author Contributions}

Larry J. Nelson contributed to conception, design, and interpretation; drafted the manuscript; and agreed to be accountable for all aspects of work ensuring integrity and accuracy. Laura M. Padilla-Walker contributed to conception, design, acquisition, analysis, and interpretation; drafted the manuscript; gave final approval. Ryan D. McLean contributed to conception, design, and interpretation; drafted the manuscript; gave final approval. 


\section{Declaration of Conflicting Interests}

The authors declared no potential conflicts of interest with respect to the research, authorship, and/or publication of this article.

\section{Funding}

The authors received no financial support for the research, authorship, and/or publication of this article.

\section{Open Practices}

Data and materials for this study have not been made publicly available. The design and analysis plans were not preregistered.

\section{ORCID iD}

Larry J. Nelson (D) https://orcid.org/0000-0001-9720-6627

\section{References}

Aarseth, E., Bean, A. M., Boonen, H., Colder Carras, M., Coulson, M., Das, D., Deleuze, J., Dunkels, E., Edman, J., Ferguson, C. J., Haagsma, M. C., Helmersson Bergmark, K., Hussain, Z., Jansz, J., Kardefelt-Winther, D., Kutner, L., Markey, P., Nielsen, R. K. L., Prause, N., ... Van Rooij, A. J. (2017). Scholars' open debate paper on the world health organization ICD-11 gaming disorder proposal. Journal of Behavioral Addictions, 6(3), 267-270.

Aquilino, W. S. (1997). From adolescent to young adult: A prospective study of parent-child relations during the transition to adulthood. Journal of Marriage and Family, 59(3), 670-686. https:// doi.org/10.2307/353953

Aquilino, W. S. (2006). Family relationships and support systems in emerging adulthood. In Emerging adults in America: Coming of age in the 21st century (pp. 193-217). American Psychological Association. https://doi.org/10.1037/11381-008

Arnett, J. J. (2004). Emerging adulthood: The winding road from the late teens through the twenties. Oxford University Press.

Barber, B. K. (1996). Parental psychological control: Revisiting a neglected construct. Child Development, 67(6), 3296-3319.

Barber, B. K., Stolz, H. E., \& Olsen, J. A. (2005). Parental support, psychological control, and behavioral control: Assessing relevance across time, culture, and method. Monographs of the Society for Research in Child Development, 70(4), 1-137. https://doi.org/10. 1111/j.1540-5834.2005.00365.x

Benjamini, Y., \& Hochberg, Y. (1995). Controlling the false discovery rate: A practical and powerful approach to multiple testing. Journal of the Royal Statistical Society B, 57(1), 289-300.

Bradley-Geist, J. C., \& Olson-Buchanan, J. B. (2014). Helicopter parents: An examination of the correlates of over-parenting of college students. Education + Training, 56(4), 314-328. https://doi.org/ 10.1108/ET-10-2012-0096

Brenning, K., Soenens, B., Mabbe, E., \& Vansteenkiste, M. (2017). Ups and downs in the joy of motherhood: Maternal well-being as a function of psychological needs, personality, and infant temperament. Journal of Happiness Studies, 20(1), 229-250. https://doi.o $\mathrm{rg} / 10.1007 / \mathrm{s} 10902-017-9936-0$

Burke, T. J., Segrin, C., \& Farris, K. L. (2018). Young adult and parent perceptions of facilitation: Associations with overparenting, family functioning, and student adjustment. Journal of Family Communication, 18(3), 233-247. https://doi.org/10.1080/15267431.2018. 1467913

Carbery, J., \& Buhrmester, D. (1998). Friendship and need fulfillment during three phases of young adulthood. Journal of Social and Personal Relationships, 15(3), 393-409. https://doi.org/10.1177/ 0265407598153005

Elder, G. H. (1994). Time, human agency, and social change: Perspectives on the life course. Social Psychology Quarterly, 57(1), 4-15. https://doi.org/10.2307/2786971

Enders, C. K., \& Bandalos, D. L. (2001). The relative performance of full information maximum likelihood estimation for missing data in structural equation models. Structural Equation Modeling, 8(3), 430-457. https://doi.org/10.1207/S15328007SE M0803_5

Fingerman, K. L., Cheng, Y. P., Wesselmann, E. D., Zarit, S., Furstenberg, F., \& Birditt, K. S. (2012). Helicopter parents and landing pad kids: Intense parental support of grown children. Journal of Marriage and Family, 74(4), 880-896. https://doi.org/10.1111/j. 1741-3737.2012.00987.x

Fingerman, K. L., \& Yahirun, J. J. (2016). Emerging adulthood in the context of family. In J. J. Arnett (Ed.), The Oxford handbook of emerging adulthood (pp. 163-176). Oxford University Press.

Fredricks, J. A., Blumenfeld, P. C., \& Paris, A. H. (2004). School engagement: Potential of the concept, state of the evidence. Review of Educational Research, 74(1), 59-109. https://doi.org/10.3102/ 00346543074001059

Gentile, D. (2009). Pathological video-game use among youth ages 8 to 18: A national study. Psychological Science, 20(5), 594-602. https://doi.org/10.1111/j.1467-9280.2009.02340.x

Gerardy, H., Mounts, N. S., Luckner, A. E., \& Valentiner, D. P. (2015). Mothers' management of adolescent peer relationships: Associations with aggressive, prosocial, and playful behavior. Journal of Genetic Psychology, 176(5), 299-314. https://doi:10. 1080/00221325.2015.1066746

Hunt, J. (2008). Make room for daddy ... and mommy: Helicopter parents are here. The Journal of Academic Administration in Higher Education, 4(1), 9-11.

Keijsers, L., \& Poulin, F. (2013). Developmental changes in parentchild communication throughout adolescence. Developmental Psychology, 49(12), 2301-2308. https://doi.org/10.1037/a0032217

Keijsers, L., Voelkle, M. C., Maciejewski, D., Branje, S., Koot, H., Hiemstra, M., \& Meeus, W. (2016). What drives developmental change in adolescent disclosure and maternal knowledge? Heterogeneity in within-family processes. Developmental Psychology, 52(12), 2057-2070. https://doi.org/10.1037/dev0000220

Kelly, L., Duran, R. L., \& Miller-Ott, A. E. (2017). Helicopter parenting and cell-phone contact between parents and children in college. Southern Communication Journal, 82(2), 102-114. https://doi.org/ 10.1080/1041794X.2017.1310286

Kouros, C. D., Pruitt, M. M., Ekas, N. V., Kiriaki, R., \& Sunderland, M. (2017). Helicopter parenting, autonomy support, and college students' mental health and well-being: The moderating role of sex and ethnicity. Journal of Child and Family Studies, 26(3), 939-949. https://doi.org/10.1007/s10826-016-0614-3 
LeMoyne, T., \& Buchanan, T. (2011). Does "hovering" matter? Helicopter parenting and its effect on well-being. Sociological Spectrum, 31(4), 399-418. https://doi.org/10.1080/02732173.2011. 574038

Lindell, A. K., Campione-Barr, N., \& Killoren, S. E. (2017). Implications of parent-child relationships for emerging adults' subjective feelings about adulthood. Journal of Family Psychology, 31(7), 810-820. https://doi.org/10.1037/fam00003 28

Little, T. D. (2013). Methodology in the social sciences. Longitudinal structural equation modeling. Guilford Press.

Lowe, K., Dotterer, A. M., \& Francisco, J. (2015). "If I Pay, I Have a Say!" Parental payment of college education and its association with helicopter parenting. Emerging Adulthood, 3(4), 286-290. https://doi.org/10.1177/2167696815579831

Luebbe, A. M., Mancini, K. J., Kiel, E. J., Spangler, B. R., Semlak, J. L., \& Fussner, L. M. (2018). Dimensionality of helicopter parenting and relations to emotional, decision-making, and academic functioning in emerging adults. Assessment, 25(7), 841-857. https://doi.org/10.1177/1073191116665907

Mahbod, M., \& Fouladchang, M. (2018). Academic entitlement in the relationship between parental over-involvement and counterproductive academic child.. Journal of Psychology, 21(4), 428-443.

Nelson, L. J., \& Padilla-Walker, L. M. (2013). Flourishing and floundering in emerging adult college students. Emerging Adulthood, 1(1), 67-78. https://doi.org/10.1177/21676968 12470938

Nelson, L. J., Padilla-Walker, L. M., Christensen, K. J., Evans, C. A., \& Carroll, J. S. (2011). Parenting in emerging adulthood: An examination of parenting clusters and correlates. Journal of Youth and Adolescence, 40(6), 730-743. https://doi.org/10.1007/s10964010-9584-8

Nelson, L. J., Padilla-Walker, L. M., \& Nielson, M. G. (2015). Is hovering smothering or loving? An examination of parental warmth as a moderator of relations between helicopter parenting and emerging adults' indices of adjustment. Emerging Adulthood, 3(4), 282-285. https://doi.org/10.1177/21676 96815576458

Novak, S. P., \& Clayton, R. R. (2001). The influence of school environment and self-regulation on transitions between stages of cigarette smoking: A multilevel analysis. Health Psychology: Official Journal of the Division of Health Psychology, American Psychological Association, 20(3), 196-207.

Olsen, S. F., Yang, C., Hart, C. H., Robinson, C. C., Wu, P., Nelson, D. A., Nelson, L. J., Jin, S., \& Jianzhong, W. (2002). Mothers' psychological control and preschool children's behavioral outcomes in China, Russia, and the United States. In B. K. Barber (Ed.), Psychological control of children and adolescents (pp. 235-262). American Psychological Association.

Padilla-Walker, L. M., Fraser, A. M., \& Harper, J. M. (2012). Walking the walk: The moderating role of proactive parenting on adolescents' value-congruent behaviors. Journal of Adolescence, 35(5), 1141-1152. https://doi.org/10.1016/j.adolescence.2012.03. 003
Padilla-Walker, L. M., \& Nelson, L. J. (2012). Black hawk down? Establishing helicopter parenting as a distinct construct from other forms of parental control during emerging adulthood. Journal of Adolescence, 35(5), 1177-1190. https://doi.org/10.1016/j.adole scence.2012.03.007

Padilla-Walker, L. M., Nelson, L. J., Carroll, J. S., \& Jensen, A. C. (2010). More than just a game: Video games, internet use, and health outcomes in emerging adults. Journal of Youth and Adolescence, 39, 103-113.

Padilla-Walker, L. M., Son, D., \& Nelson, L. J. (2019). Profiles of helicopter parenting, parental warmth, and psychological control during emerging adulthood. Emerging Adulthood. https:/doi.org/ $10.1177 / 2167696818823626$

Pettit, G. S., Clawson, M. A., Dodge, K. A., \& Bates, J. E. (1996). Stability and change in peer-rejected status: The role of child behavior, parenting, and family ecology. Merrill-Palmer Quarterly, 42(2), 267-294.

Robinson, C., Mandleco, B., Roper, S., \& Hart, C. (2001). The Parenting Styles and Dimensions Questionnaire (PSDQ). Handbook of Family Measurement Techniques, 3, 319-321.

Rodríguez, C. M., Pu, D. F., \& Foiles, A. R. (2019). Cognitiveaffective pathways to child depressive and anxious symptoms: Role of children's discipline attributions. Child Psychiatry \& Human Development, 50(1), 163-171.

Rousseau, S., \& Scharf, M. (2015). "I will guide you" The indirect link between overparenting and young adults' adjustment. Psychiatry Research, 228(3), 826-834. https://doi.org/10.1016/j.psychres. 2015.05.016

Russell, L. L. H., \& Johnson, E. I. (2017). Parenting emerging adults who game excessively: Parents' lived experiences. Issues in Mental Health Nursing, 38(1), 66-74. https://doi.org/10.1080/ 01612840.2016 .1253808

Schiffrin, H. H., Erchull, M. J., Sendrick, E., Yost, J. C., Power, V. , \& Saldanha, E. R. (2019). The effects of maternal and paternal helicopter parenting on the self-determination and well-being of emerging adults. Journal of Child and Family Studies, 28(12), 3346-3359. https://doi.org/10.1007/s10826-019-01513-6

Schiffrin, H. H., Godfrey, H., Liss, M., \& Erchull, M. J. (2015). Intensive parenting: Does it have the desired impact on child outcomes? Journal of Child and Family Studies, 24(8), 2322-2331. https:// doi.org/10.1007/s10826-014-0035-0

Schiffrin, H. H., \& Liss, M. (2017). The effects of helicopter parenting on academic motivation. Journal of Child and Family Studies, 26(5), 1472-1480. https://doi.org/10.1007/s10826-017-0658-z

Segrin, C., Woszidlo, A., Givertz, M., Bauer, A., \& Taylor Murphy, M. (2012). The association between overparenting, parent-child communication, and entitlement and adaptive traits in adult children. Family Relations, 61(2), 237-252. https://doi.org/10.1111/j. 1741-3729.2011.00689.x

Segrin, C., Woszidlo, A., Givertz, M., \& Montgomery, N. (2013). Parent and child traits associated with overparenting. Journal of Social and Clinical Psychology, 32(6), 569-595. https://doi.org/10.1521/ jscp.2013.32.6.569

Soenens, B., Vansteenkiste, M., \& Beyers, W. (2019). Parenting adolescents. In M. Bornstein (Ed.), Handbook of parenting: 
Children and parenting (3rd ed., Vol. 1, pp. 101-167). Routledge.

van Ingen, D. J., Freiheit, S. R., Steinfeldt, J. A., Moore, L. L., Wimer, D. J., Knutt, A. D., Scapinello, S., \& Roberts, A. (2015). Helicopter parenting: The effect of an overbearing caregiving style on peer attachment and self-efficacy. Journal of College Counseling, 18(1), 7-20. https://doi.org/10.1002/j.21611882.2015.00065.x

Weissman, M. M., Orvaschel, H., \& Padian, N. (1980). Children's symptom and social functioning self-report scales: Comparison of mothers' and children's reports. Journal of Nervous and Mental Disease, 168(12), 736-740. https://doi.org/10.1097/00005053198012000-00005

\section{Author Biographies}

Larry J. Nelson is a professor in the School of Family Life at Brigham Young University. He studies flourishing and floundering during emerging adulthood.

Laura M. Padilla-Walker is a professor in the School of Family Life at Brigham Young University. She studies parenting and child development during adolescence and emerging adulthood.

Ryan D. McLean is a MS student in Marriage, Family, and Human Development at Brigham Young University. He studies media use and parenting during adolescence and emerging adulthood. 